\title{
Kinetic, infrared, and X-ray absorption studies of adsorption, desorption, and reactions of thiophene on H-ZSM5 and Co/H-ZSM5
}

\author{
Sara Y. Yu, ${ }^{a}$ Javier Garcia-Martinez, $\dagger^{a}$ Wei Li, $\ddagger^{a}$ George D. Meitzner ${ }^{b}$ and Enrique Iglesia*a
}

${ }^{a}$ Department of Chemical Engineering, University of California at Berkeley, 94720

Berkeley, CA, USA. E-mail: iglesia@cchem.berkeley.edu; Fax: 510-642-4778

${ }^{b}$ Edge Analytical, Inc., 2126 Allen Blvd. \#3, 53562 Middleton, WI, USA

Received 24th September 2001, Accepted 19th December 2001

First published as an Advance Article on the web 22nd February 2002

Temperature programmed desorption and infrared and X-ray absorption near-edge spectroscopies were used during adsorption and reactions of thiophene in order to probe adsorbed intermediates and catalytic structures responsible for thiophene reactions with propane or $\mathrm{H}_{2}$ on $\mathrm{H}-\mathrm{ZSM} 5$ and $\mathrm{Co} / \mathrm{H}-\mathrm{ZSM}$ 5. Infrared spectra showed that thiophene interacts with acidic $\mathrm{OH}$ groups in H-ZSM5 via hydrogen bonding at ambient temperature. No additional bands were detected on $\mathrm{Co} / \mathrm{H}-\mathrm{ZSM} 5$, suggesting the absence of specific interactions with Co cations. During adsorption at ambient temperatures, infrared bands assigned to $\mathrm{CH}_{2}$ groups near $\mathrm{C}=\mathrm{C}$ bonds or $\mathrm{S}$ atoms and to $\mathrm{S}-\mathrm{H}$ species were detected and H-ZSM5 and Co/H-ZSM5 acquired colors typical of thiophene oligomers. Slightly above ambient temperatures, benzene and $\mathrm{H}_{2} \mathrm{~S}$ formed from pre-adsorbed thiophene. These results indicate that hydrogen-bonded thiophene undergoes ring opening or oligomerization near ambient temperature on acidic OH groups in H-ZSM5. Some of the adsorbed thiophene (20-50\%) interacts weakly with channel walls or with residual $\mathrm{Na}$ cations and desorbs unreacted. The remaining adsorbed thiophene desorbs as $\mathrm{H}_{2} \mathrm{~S}$, aromatic hydrocarbons, and organosulfur compounds, such as methylthiophene and benzothiophene, or forms irreversibly adsorbed unsaturated organic deposits. In situ infrared studies during thiophene and thiophene-propane reactions at $773 \mathrm{~K}$ on H-ZSM5 and Co/H-ZSM5 showed that surface coverages of thiophene-derived intermediates were low on acidic $\mathrm{OH}$ groups and Co cations. Co K-edge X-ray absorption near-edge spectra measured during these reactions confirmed that $\mathrm{Co}^{2+}$ cations do not reduce or sulfide; their local environment, however, changes slightly, apparently because of interactions of strongly adsorbed species with Co cations. Sulfur K-edge X-ray absorption spectra detected small amounts of organosulfur species, but no inorganic sulfides, after thiophene, thiophene- $\mathrm{H}_{2}$, and thiophene-propane reactions, consistent with the observed stability of exchanged cations against reduction and sulfidation. S : Al ratios were less than 0.04 at. on all samples; these amounts represent less than $1 \%$ of the $\mathrm{S}$-atoms removed from thiophene as $\mathrm{H}_{2} \mathrm{~S}$ during catalytic propane-thiophene reactions.

\section{Introduction}

Recent studies have shown that thiophene desulfurization proceeds with the selective formation of $\mathrm{H}_{2} \mathrm{~S}$ and sulfur-free hydrocarbons using hydrogen species and alkenes formed in concurrent propane dehydrogenation and aromatization reactions on H-ZSM5 and cation-exchanged H-ZSM5. ${ }^{1,2}$ The reaction occurs without significant involvement of the $\mathrm{H}_{2}$ molecules formed in propane dehydrogenation reactions. The reaction pathways involved in the kinetic coupling of thiophene and propane reactions were discussed previously. ${ }^{3,4}$ In this previous study, it was mentioned that the coverage of acidic $\mathrm{OH}$ groups by intermediates derived from thiophene or propane was very low during reaction; no thiophene adsorption on acid sites was detected during propane-thiophene reactions at $773 \mathrm{~K}$ on $\mathrm{H}-\mathrm{ZSM} 5$ or $\mathrm{Co} / \mathrm{H}-\mathrm{ZSM} 5$. It was also stated, without the experimental evidence, that in situ X-ray absorption spectroscopy did not detect any marked changes in the local structure or oxidation state of the

\footnotetext{
$\dagger$ Permanent address: Departamento de Quimica Inorganica, Universidad de Alicante, Alicante, Spain.

$\ddagger$ Current address: Research and Development Center, General Motors Corporation, Mail Code 480-106-185, Warren, MI 48090, USA.
}

exchanged $\mathrm{Co}^{2+}$ cations. The experimental evidence for these statements, and its implications for the mechanism and site requirements of thiophene desulfurization reactions, are presented here together with complementary studies of the desorption and chemical reactions of thiophene pre-adsorbed on H-ZSM5 and Co/H-ZSM5. Temperature-programmed desorption of pre-adsorbed thiophene, and infrared and X-ray absorption near-edge (XANES) spectra collected during adsorption and reactions of thiophene, were used to explore possible reactive intermediates and catalytic structures present during reactions of thiophene with either propane or $\mathrm{H}_{2}$ on $\mathrm{H}$ ZSM5 and Co/H-ZSM5.

Studies investigating the interactions of thiophene with different acidic zeolites and alumina-based materials have been reported. ${ }^{5-10}$ Garcia and Lercher used infrared spectroscopy to examine the adsorption and surface chemistry of thiophene on H-ZSM5, Na-ZSM5, and K-ZSM5 near ambient temperature and during subsequent temperature ramping. ${ }^{5,6}$ The products evolved were identified using mass spectrometry, but without measurements of the amounts desorbed. Here, we bring together results obtained from infrared spectroscopy during thiophene adsorption at ambient temperature and during subsequent thermal treatments in $\mathrm{He}$, with temperature programmed desorption studies on H-ZSM5 and $\mathrm{Co} /$ H-ZSM5, during which we monitor the adsorption, purge, 
and desorption stages using quantitative mass spectrometry. We attempt to determine the identity and amount of the products formed using gas chromatography. These experiments aim to probe the interactions and reactions of thiophene on $\mathrm{H}-\mathrm{ZSM} 5$ and $\mathrm{Co} / \mathrm{H}-\mathrm{ZSM} 5$ at ambient temperature and during subsequent desorption or reactions of thiophene as the temperature increases. In addition, infrared studies during reactions of thiophene and thiophene-propane mixtures at $773 \mathrm{~K}$ on $\mathrm{H}-\mathrm{ZSM} 5$ and $\mathrm{Co} / \mathrm{H}-\mathrm{ZSM} 5$ were used to probe the interactions of propane and thiophene with acid sites or metal cations during steady-state catalytic reactions.

In situ Co K-edge XANES was used to detect any structural changes of Co cations in Co/H-ZSM5 during thiophene-propane reactions, and specifically any reduction or sulfidation of these cations in the presence of thiophene. Sulfur K-edge X-ray absorption was used to determine the amount and type of sulfur species retained by the catalysts after thiophene reactions.

\section{Experimental methods}

\section{Catalyst synthesis}

Na-ZSM5 (Zeochem, $\mathrm{Si}: \mathrm{Al}=14.5)(\sim 20 \mathrm{~g})$ was converted to $\mathrm{NH}_{4}$-ZSM5 by three exchanges with $0.5 \mathrm{M}$ aqueous $\mathrm{NH}_{4} \mathrm{NO}_{3}$ (Aldrich, 99.999\%) solutions (1 L exchange solution) at $353 \mathrm{~K}$. The samples were filtered and washed with $2 \mathrm{~L}$ deionized water, treated in ambient air at $398 \mathrm{~K}$ overnight, and then in flowing dry air (Airgas, zero grade) at $773 \mathrm{~K}$ for $20 \mathrm{~h}$ in order to form H-ZSM5. Co/H-ZSM5 samples were prepared by aqueous exchange of H-ZSM5 $(\sim 2.5 \mathrm{~g})$ at $353 \mathrm{~K}$ for varying periods of time using a $0.05 \mathrm{M}$ aqueous solution of cobalt nitrate $\left[\mathrm{Co}\left(\mathrm{NO}_{3}\right)_{2} \cdot 6 \mathrm{H}_{2} \mathrm{O}\right.$, Aldrich, $99 \%$ ] (1 L exchange solution). After exchange, samples were filtered to retain the solids, which were washed with $2 \mathrm{~L}$ deionized water, dried in ambient air at $398 \mathrm{~K}$ overnight, and treated in flowing dry air (Airgas, zero grade) at $773 \mathrm{~K}$ for $20 \mathrm{~h}$. The Co and $\mathrm{Na}$ content were measured by atomic absorption spectroscopy (Galbraith Laboratories, Inc.). The $\mathrm{Na}$ content in H-ZSM5 and $\mathrm{Co} / \mathrm{H}-$ ZSM5 were below $0.14 \mathrm{wt} . \%$. The structural characterization and catalytic behavior of these H-ZSM5 and Co/H-ZSM5 samples were reported previously. ${ }^{1,11-13}$

\section{In situ infrared spectroscopic studies}

Infrared spectra were collected using a Fourier-transform infrared spectrometer (Mattson, Research Series 10000) and a Praying-Mantis diffuse reflectance attachment (Harrick Scientific, DRP-XXX) with a controlled environment flow cell (Harrick Scientific, HVC-DR2). The cell was equipped with $\mathrm{CaF}_{2}$ windows. Catalyst powder samples were placed within a cylindrical receptacle on top of a porous quartz disk and gases flowed upwards through the disk and the sample. Samples were treated in flowing dry air (Airgas, zero grade) for 1 $\mathrm{h}$ at $773 \mathrm{~K}$ before thiophene adsorption. Thiophene (Aldrich, $>99 \%, 1 \mathrm{kPa}$ ) in a $\mathrm{He}$ (Praxair, UHP) or $\mathrm{H}_{2}$ (Praxair, UHP) carrier was passed through samples at ambient temperature in order to probe the thiophene interactions during adsorption at low temperatures. Thiophene was then removed from the $\mathrm{He}$ or $\mathrm{H}_{2}$ carrier and the temperature increased in flowing $\mathrm{He}$ to $773 \mathrm{~K}$ at $0.167 \mathrm{~K} \mathrm{~s}^{-1}$. In-situ infrared spectra were also measured during thiophene and thiophene-propane (Praxair, $>99.5 \%$ ) reactions at $773 \mathrm{~K}$ on $\mathrm{H}-\mathrm{ZSM} 5$ and $\mathrm{Co} / \mathrm{H}-$ ZSM5. Diffuse reflectance measurements were converted to pseudo-absorbances using the Kubelka-Munk function. ${ }^{14}$ $\mathrm{KBr}$ was used to collect a background spectrum at the same temperature as the zeolite samples. Spectra were collected in the $1000-4000 \mathrm{~cm}^{-1}$ wavenumber range with a resolution of $4 \mathrm{~cm}^{-1}$.
Temperature programmed desorption and reactions of adsorbed thiophene

The kinetics of desorption and chemical reactions of adsorbed thiophene on $\mathrm{H}-\mathrm{ZSM} 5, \mathrm{Co} / \mathrm{H}-\mathrm{ZSM} 5(\mathrm{Co} / \mathrm{Al}=0.12)$, and Na-ZSM5 were measured as the sample temperature was increased using a flow microreactor. Samples were first treated in flowing dry air (Airgas, zero grade) for $1 \mathrm{~h}$ at $773 \mathrm{~K}$. Helium (Praxair, UHP) was then used to purge the reactor for $0.5 \mathrm{~h}$, as it was cooled from $773 \mathrm{~K}$ to ambient temperature. Thiophene was adsorbed by exposing samples to thiophene $(1 \mathrm{kPa})$ in a flow of either He (Praxair, UHP) or $\mathrm{H}_{2}$ (Praxair, UHP) at ambient temperature for $0.33 \mathrm{~h}$. Thiophene was then removed from the carrier gas and weakly-adsorbed thiophene was desorbed by flowing the carrier gas for an additional $1 \mathrm{~h}$. The temperature was then increased to $773 \mathrm{~K}$ at $0.167 \mathrm{~K} \mathrm{~s}^{-1}$ and held at $773 \mathrm{~K}$ for $1 \mathrm{~h}$. The effluent was analyzed continuously during adsorption, purge, and desorption/reaction steps using an on-line mass spectrometer (Leybold Inficon Inc., Transpector). In addition, syringe samples of the effluent were collected for gas chromatographic analysis (Hewlett-Packard 6890) using capillary (HP-1 crosslinked methyl-silicone, $50 \mathrm{~m} \times 0.32 \mathrm{~mm}$, $1.05 \mu$ film) and packed (Hayesep-Q, 80/100 mesh, $\left.10^{\prime} \times 0.125^{\prime \prime}\right)$ columns and flame ionization and thermal conductivity detection. Both mass spectrometry and gas chromatography data were used in order to identify products and to measure the concentrations of thiophene and reaction products. The following masses were used for each reaction product: $\mathrm{H}_{2} \mathrm{~S}(34 \mathrm{amu})$, benzene (78 amu), toluene (91 amu), methylthiophene (97 amu), and benzothiophene (134 amu).

\section{Cobalt K-edge XANES during thiophene-propane reactions}

Cobalt K-edge X-ray absorption studies were carried out at the Stanford Synchrotron Research Laboratory (SSRL) using beamlines 2-3 and 4-1 and an unfocused $\mathrm{Si}$ (111) double-crystal upward-reflecting monochromator with parallel geometry. The spectra were acquired at $5 \mathrm{eV}$ increments between 7461-7691 $\mathrm{eV}, 0.35 \mathrm{eV}$ increments from 7691 to $7730 \mathrm{eV}$, and $0.04 \mathrm{~A}^{-1}$ increments from 7730 to $8791 \mathrm{eV}$. The intensities of the incident photon beam, the transmitted beam after the sample, and the transmitted beam after a reference Co foil were measured using three $\mathrm{N}_{2}$-purged ionization chambers. The energy was calibrated by simultaneously measuring the spectrum of the sample and of the Co foil and fixing the first inflection point in the Co foil spectrum at its reported absorption energy $(7709 \mathrm{eV})$. X-ray absorption spectra were measured using an in situ capillary cell and a portable gas feed manifold. ${ }^{15}$ Samples were treated in flowing dry air (Airgas, zero grade) at $773 \mathrm{~K}$ before in situ measurements. Spectra were acquired during thiophene (Aldrich, > 99\%)/propane (Praxair, > 99.5\%) reactions at $773 \mathrm{~K}$. The X-ray absorption spectrum of cobalt sulfide (Alfa Aesar, 99.5\%) was also collected at ambient conditions for comparison. This sample was diluted with boron nitride to obtain a $5 \mathrm{wt} . \%$ Co sample. X-ray absorption data were analyzed using WinXAS (version 1.2). ${ }^{16,17}$ A linear fit to the pre-edge region was subtracted from the spectra, and they were then normalized using a fifth-order polynomial fit to the post-edge fine structure (EXAFS) region.

\section{Sulfur K-edge XANES}

Sulfur K-edge X-ray absorption studies were also performed at the Stanford Synchrotron Research Laboratory (SSRL) using beamline 6-2 with an unfocused Si (111) double-crystal upward-reflecting monochromator with parallel geometry. The spectra were collected using a Lytle cell and a fluorescence detector ${ }^{18}$ both purged with $\mathrm{He}$ at $1.67 \mathrm{~cm}^{3} \mathrm{~s}^{-1}$. The spectra were taken at $0.125 \mathrm{eV}$ increments in the 2460 to $2490 \mathrm{eV}$ energy region. The beam path was also purged with He. 
$\mathrm{Na}_{2} \mathrm{~S}_{2} \mathrm{O}_{3}$ was used as a reference compound and the edge energies of $\mathrm{S}^{2-}$ and $\mathrm{S}^{6+}$ in $\mathrm{Na}_{2} \mathrm{~S}_{2} \mathrm{O}_{3}$ were assumed to be located at 2468.6 and $2477.5 \mathrm{eV}$, respectively. Spectra were measured on samples exposed to ambient air at room temperature after reactions of thiophene, thiophene $/ \mathrm{H}_{2}$, or thiophene/propane reactants at $773 \mathrm{~K}$ for about $2 \mathrm{~h}$. The catalyst samples were

(a)

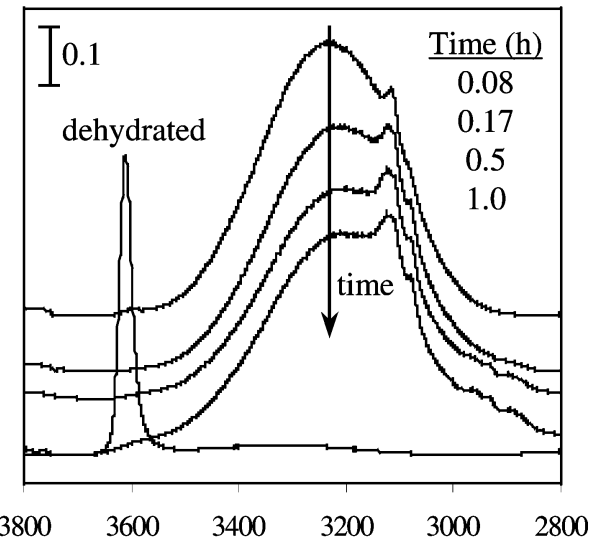

(b)

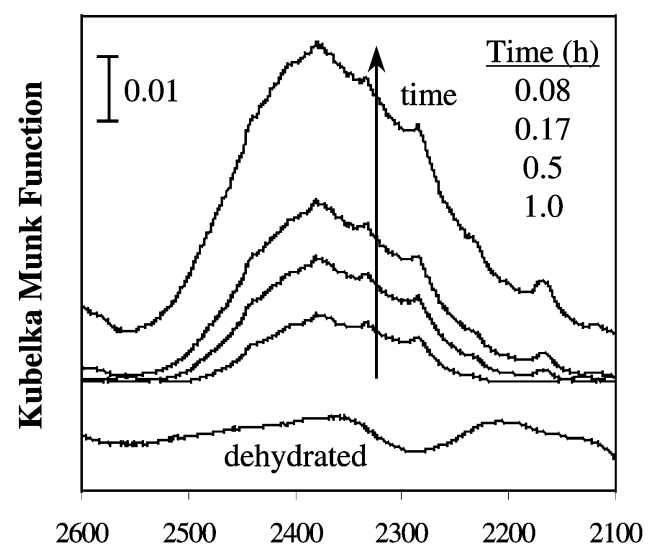

(c)

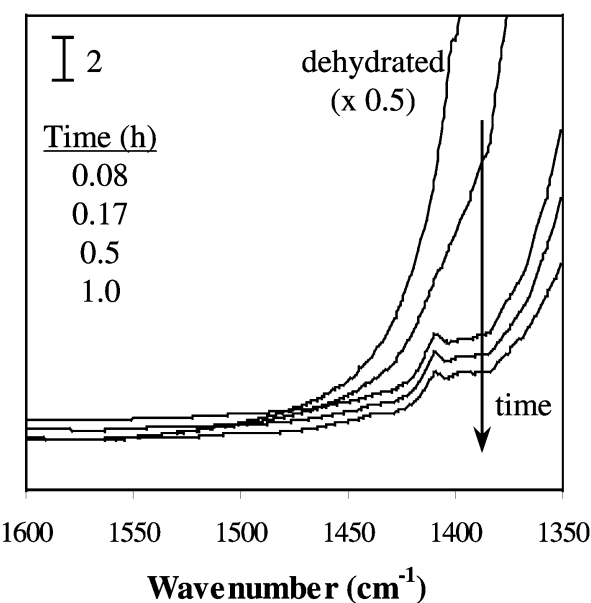

Fig. 1 (a) Infrared spectra of $\mathrm{OH}$ region of $\mathrm{H}-\mathrm{ZSM} 5(\mathrm{Si} / \mathrm{Al}=14.5)$ in contact with thiophene/He at $303 \mathrm{~K}$ with increasing time compared to spectrum of dehydrated sample in He at $773 \mathrm{~K}$. (b) Infrared spectra of hydrogen bonding between $\mathrm{SH}$ groups in mercaptans and acidic $\mathrm{OH}$ groups on $\mathrm{H}-\mathrm{ZSM} 5(\mathrm{Si}: \mathrm{Al}=14.5)$ in contact with thiophene : He at $303 \mathrm{~K}$ with increasing time compared to spectrum of dehydrated sample in $\mathrm{He}$ at $773 \mathrm{~K}$. (c) Infrared spectra of deformation vibrations of $\mathrm{CH}_{2}$ groups close to a double bond $\left({ }^{*} \mathrm{CH}_{2}-\mathrm{CH}=\mathrm{CH}_{2}\right)$ or a sulfur atom $\left({ }^{*} \mathrm{CH}_{2}-\mathrm{S}-\right)$ of H-ZSM5 $(\mathrm{Si}: \mathrm{Al}=14.5)$ in contact with thiophene : He at $303 \mathrm{~K}$ with increasing time compared to spectrum of dehydrated sample in $\mathrm{He}$ at $773 \mathrm{~K}$. mounted using Kapton tape and spectra were measured at ambient temperature.

\section{Results and discussion}

\section{Infrared spectroscopy studies}

Infrared spectra of adsorbed thiophene and of $\mathrm{OH}$ groups in H-ZSM5 and Co/H-ZSM5 were measured both during the initial adsorption of thiophene at ambient temperature and during treatment in He with increasing temperature. The infrared spectra of thiophene adsorbed on H-ZSM5 at $303 \mathrm{~K}$ are shown in Fig. 1a-c as a function of time of contact with thiophene. These spectra are compared to the initial spectrum of $\mathrm{H}-\mathrm{ZSM} 5$ after dehydration in $\mathrm{He}$ at $773 \mathrm{~K}$ and before thiophene adsorption in these figures.

The band at $3610 \mathrm{~cm}^{-1}$ in fresh H-ZSM5 samples (Fig. 1a) corresponds to acidic $\mathrm{OH}$ groups at framework $\mathrm{Al}$ sites in $\mathrm{H}$ ZSM5. ${ }^{19-21}$ The adsorption of thiophene at ambient temperature led to the disappearance of this band and to its replacement by a broader band centered at $\sim 3200 \mathrm{~cm}^{-1}$ (Fig. 1a). These spectral changes reflect hydrogen-bonding interactions of thiophene with acidic OH groups in H-ZSM5.

As H-ZSM5 remained in contact with thiophene for longer times, the intensity of this broad band at $\sim 3200 \mathrm{~cm}^{-1}$ decreased (Fig. 1a) and the intensity of new bands at 2900 $\mathrm{cm}^{-1}, 2350 \mathrm{~cm}^{-1}$, and $1410 \mathrm{~cm}^{-1}$ increased. The band at $3610 \mathrm{~cm}^{-1}$ for free acidic OH groups, however, was not restored (Fig. 1a-c). Also, infrared bands appeared at 3120, 3080 , and $1250 \mathrm{~cm}^{-1}$ - they correspond to a condensed thiophene phase within zeolite channels. The band at $2900 \mathrm{~cm}^{-1}$ is assigned to stretching vibrations of $\mathrm{CH}_{2}$ groups located near a $\mathrm{C}-\mathrm{C}$ double bond (e.g., $\left.{ }^{*} \mathrm{CH}_{2}-\mathrm{CH}=\mathrm{CH}_{2}\right)($ Scheme 1a) or a sulfur atom (e.g., ${ }^{*} \mathrm{CH}_{2}-\mathrm{S}-$ ) (Scheme $\left.1 b\right) .{ }^{5}$ The band at 2350 $\mathrm{cm}^{-1}$ has been assigned to an interaction similar to the hydrogen bonding between $\mathrm{S}-\mathrm{H}$ groups in mercaptans and $\mathrm{O}-\mathrm{H}$ groups. ${ }^{5}$ The band at $1410 \mathrm{~cm}^{-1}$ is assigned to the fundamental ring stretching vibration due to hydrogen bonding of thiophene. ${ }^{5} \mathrm{On} \mathrm{H}-\mathrm{Y}$ this band is attributed to conjugated $\mathrm{C}=\mathrm{C}$ bonds, ${ }^{7}$ while on $\gamma-\mathrm{Al}_{2} \mathrm{O}_{3}$, it was assigned to weakly bonded thiophene species present at high coverages. ${ }^{9}$ These spectral changes show that thiophene molecules initially attached to $\mathrm{OH}$ groups via weak hydrogen bonding at ambient temperatures react at $\sim 303 \mathrm{~K}$ to form products that remain adsorbed on acidic $\mathrm{OH}$ groups.

Garcia and Lercher assigned the $2900 \mathrm{~cm}^{-1}$ and $2350 \mathrm{~cm}^{-1}$ bands to an alkene-thiol species formed via ring opening of thiophene. ${ }^{5}$ Saintigny et al. carried out molecular simulations of thiophene adsorption and reactions of thiophene on acid sites. $^{22}$ Their proposed ring opening and desulfurization reactions do not lead to $\mathrm{CH}_{2}$ groups near a $\mathrm{C}-\mathrm{C}$ double bond or sulfur atom, but they involve a $\mathrm{S}-\mathrm{H}$ group hydrogen-bonded to an acidic $\mathrm{OH}^{22}$ The $\mathrm{S}-\mathrm{H}$ bands in the spectra of thiophene adsorbed near ambient temperatures may indicate that ring opening occurs at these low temperatures. The band corre-<smiles>CC=CC=CC</smiles>

(a)<smiles>C[CH]SC</smiles>

(b)

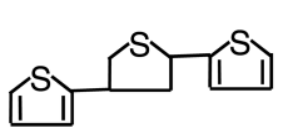

(c)

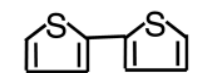

(d)

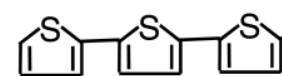

(e)
Scheme 1 Structures of (a) $\mathrm{CH}_{2}$ group near a $\mathrm{C}-\mathrm{C}$ double bond, (b) $\mathrm{CH}_{2}$ group near a sulfur atom, (c) 2,4-di-(thienyl)-thiolane, (d) dimeric thiophene, and (e) trimeric thiophene. 
sponding to $\mathrm{CH}_{2}$ groups located near a $\mathrm{C}-\mathrm{C}$ double bond or to a sulfur atom and liquid thiophene are likely to arise from thiophene oligomers. Oligomers of thiophene such as 2,4-di(thienyl)-thiolane (Scheme 1c), thiophene dimers (Scheme 1d), and trimers (Scheme 1e) form on acid catalysts. ${ }^{23-25}$ These thiophene oligomerization reactions are discussed in more detail below.

The infrared spectra for $\mathrm{Co} / \mathrm{H}-\mathrm{ZSM} 5$ after exposure to thiophene were very similar to those obtained on H-ZSM5. Thus, it appears that Co cations did not bind thiophene species as infrared-active structures near ambient temperatures. During thiophene adsorption on Na-ZSM5, Garcia and Lercher observed infrared bands at 3109 and $3089 \mathrm{~cm}^{-1}$, corresponding to $\mathrm{C}-\mathrm{H}$ stretching vibrations, and a band at $1396 \mathrm{~cm}^{-1}$, which they assigned to a perturbed ring stretching vibration $\nu_{5}$ in species interacting strongly with cations. ${ }^{5}$ Therefore, we would expect that an electron-rich molecule, such as thiophene, would interact with Co cations acting as Lewis acids. Bands similar to those observed by Garcia and Lercher on Na$\mathrm{ZSM}^{5}$ may be present in $\mathrm{Co} / \mathrm{H}-\mathrm{ZSM} 5$ but may have been obscured by the broad bands at $\sim 3100 \mathrm{~cm}^{-1}$ corresponding to condensed thiophene. These condensed thiophene bands were not detected in previous studies ${ }^{5}$ because of the much lower thiophene pressures used $\left(10^{-6}-10^{-1} \mathrm{kPa} v s .1 \mathrm{kPa}\right.$ here). The $\mathrm{OH}$ bands in the fresh sample and the bands corresponding to $\mathrm{OH}$ perturbed by hydrogen-bonded thiophene were unaffected by the presence of cations, but their intensities were slightly lower because some of the $\mathrm{OH}$ groups were replaced by Co during exchange. ${ }^{3}$ Co cations decrease the number of acidic $\mathrm{OH}$ groups but not their chemical properties. This was shown by comparing infrared spectra for pyridine adsorbed on $\mathrm{Co} /$ H-ZSM5 and on H-ZSM5 and noting that the frequency of the adsorbed pyridine bands was not affected by Co cations. ${ }^{26}$ In addition, the adsorption of thiophene with $\mathrm{H}_{2}$ or $\mathrm{He}$ as a carrier gas led to identical spectra, as expected from the absence of $\mathrm{H}_{2}$ activation pathways at ambient temperatures on either H-ZSM5 or Co/H-ZSM5.

Fig. 2a-c show infrared spectra of H-ZSM5 during thermal treatment of pre-adsorbed thiophene $(303 \mathrm{~K}, 1 \mathrm{~h})$ using $\mathrm{He}$ as a carrier gas. The broad band at $3200 \mathrm{~cm}^{-1}$ became weaker as temperature increased (Fig. 2a). At $373 \mathrm{~K}$, the intensity of the broad band at $3200 \mathrm{~cm}^{-1}$ weakened without any significant recovery of the $3610 \mathrm{~cm}^{-1}$ band corresponding to unperturbed acidic $\mathrm{OH}$ groups (Fig. 2a). This indicates that hydrogenbonded thiophene continues to react as the sample is heated above ambient temperature. The broad band at $3200 \mathrm{~cm}^{-1}$ continues to weaken and the intensity of the free acidic $\mathrm{OH}$ band is fully recovered as the temperature increases, indicating that products are formed by desorption of species adsorbed on acidic $\mathrm{OH}$ groups. The bands at $2900 \mathrm{~cm}^{-1}$, corresponding to $\mathrm{CH}_{2}$ groups near a $\mathrm{C}-\mathrm{C}$ double bond or sulfur atom, and the band at $1410 \mathrm{~cm}^{-1}$ for hydrogen-bonded thiophene, ${ }^{5}$ conjugated $\mathrm{C}=\mathrm{C}$ bonds, ${ }^{7}$ or high-coverage thiophene species, ${ }^{9}$ respectively, became initially more intense with increasing temperature, but ultimately weakened at higher temperatures (Fig. $2 \mathrm{a}-\mathrm{c})$. The $2350 \mathrm{~cm}^{-1}$ band for hydrogen-bonded $\mathrm{S}-\mathrm{H}$ at $\mathrm{OH}$ groups also weakened with increasing temperature (Fig. 2b). The analysis of the effluent stream (reported below) shows that $\mathrm{H}_{2} \mathrm{~S}$ and benzene were evolved in this temperature range. The spectral and product evolution described here for H-ZSM5 are similar to those measured on Co/H-ZSM5 samples.

A quantitative analysis of these infrared data was carried out using the integrated intensity of the $1410 \mathrm{~cm}^{-1}$ band (Fig. 2c), corresponding to thiophene species or conjugated $\mathrm{C}=\mathrm{C}$ bonds as a function of temperature (Fig. 3). This integrated intensity was normalized using that for the zeolite framework band at $1200 \mathrm{~cm}^{-1}$, which corresponds to framework vibrations and it is used here as an internal standard. The concentration of these intermediates increased as temperature increased from 300 to $450 \mathrm{~K}$, and then decreased
(A)
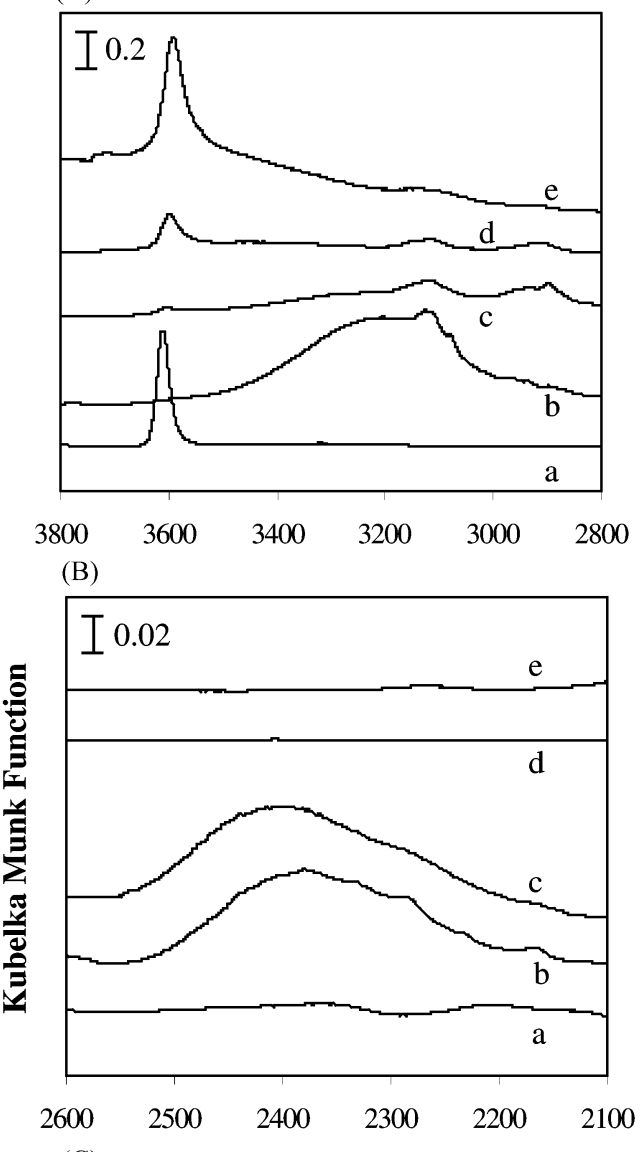

(C)

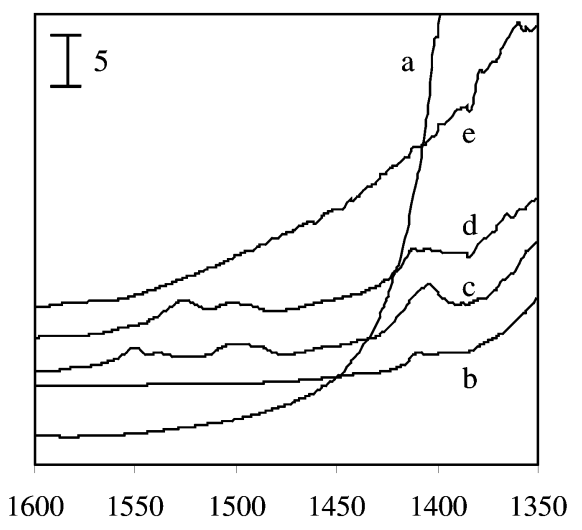

Wavenumber $\left(\mathrm{cm}^{-1}\right)$

Fig. 2 (A) Infrared spectra of $\mathrm{OH}$ region of (a) dehydrated H-ZSM5 sample $(\mathrm{Si} / \mathrm{Al}=14.5)$, (b) thiophene adsorbed in He stream after $1 \mathrm{~h}$, and adsorbed thiophene during treatment in $\mathrm{He}$ at (c) $373 \mathrm{~K}$ (d) $573 \mathrm{~K}$ (e) $773 \mathrm{~K}$. (B) Infrared spectra of hydrogen bonding between $\mathrm{SH}$ groups in mercaptans and acidic $\mathrm{OH}$ groups of (a) dehydrated $\mathrm{H}$ ZSM5 sample $(\mathrm{Si} / \mathrm{Al}=14.5)$, (b) thiophene adsorbed in He stream after $1 \mathrm{~h}$, and adsorbed thiophene during treatment in He at (c) 373 $\mathrm{K}$ (d) $573 \mathrm{~K}$ (e) $773 \mathrm{~K}$. (C) Infrared spectra of deformation vibrations of $\mathrm{CH}_{2}$ groups close to a double bond $\left({ }^{*} \mathrm{CH}_{2}-\mathrm{CH}=\mathrm{CH}_{2}\right)$ or a sulfur atom ( $\left.{ }^{*} \mathrm{CH}_{2}-\mathrm{S}-\right)$ of (a) dehydrated $\mathrm{H}-\mathrm{ZSM} 5$ sample ( $\left.\mathrm{Si} / \mathrm{Al}=14.5\right)$, (b) thiophene adsorbed in He stream after $1 \mathrm{~h}$, and adsorbed thiophene during treatment in $\mathrm{He}$ at (c) $373 \mathrm{~K}$ (d) $573 \mathrm{~K}$ (e) $773 \mathrm{~K}$.

at higher temperatures. Ring opening and oligomerization appear to be initially favored by higher temperatures, but ultimately the products formed either desorb or dehydrogenate further into active organic or organosulfur surface species with lower infrared absorption cross-sections. The band at 1410 $\mathrm{cm}^{-1}$, corresponding to these intermediates, is also detected on $\mathrm{Co} / \mathrm{H}-\mathrm{ZSM} 5$, suggesting that Co cations do not influence 


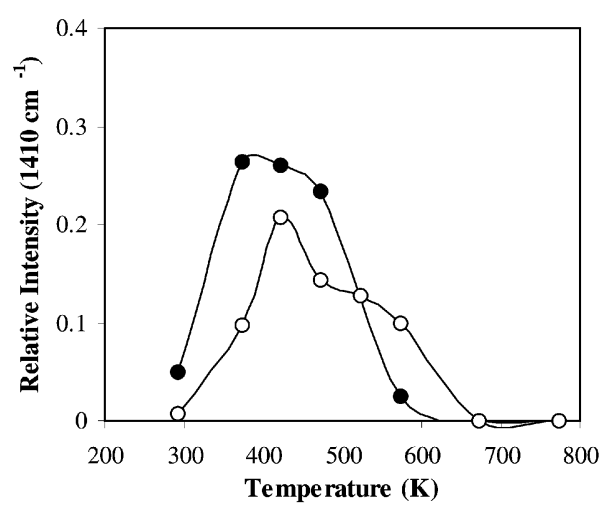

Fig. 3 Intensity of infrared band at $1410 \mathrm{~cm}^{-1}\left(\mathrm{CH}_{2}\right.$ groups close to a double bond or sulfur atom) relative to infrared band at $1200 \mathrm{~cm}^{-1}$ (zeolite $\mathrm{T}-\mathrm{O}-\mathrm{T}$ framework) during thiophene temperature programmed desorption in $\mathrm{He}$ on H-ZSM5 (•) and Co/H-ZSM5 (O) $[\mathrm{Si} / \mathrm{Al}=14.5, \mathrm{Co} / \mathrm{Al}=0.17]$.

the density or type of adsorbed species. Co cations led to the retention of these adsorbed intermediates up to higher temperatures when He was used as the carrier gas. This may reflect the greater extent of unsaturation of adsorbed species when Co cations are present and provide sites for the removal of $\mathrm{H}_{2}$ as the temperature increases. These hydrogen-deficient species are expected to bind more strongly to surface sites. Indeed, the analysis of the effluent stream discussed below shows that some larger products (e.g. toluene and methylthiophene) desorb at higher temperatures on Co/H-ZSM5 than on H-ZSM5.

The role of acidic $\mathrm{OH}$ groups in thiophene adsorption and reactions was inferred from in situ infrared spectra of $\mathrm{Na}$ ZSM5 during thiophene adsorption at ambient temperature and during heating in a $\mathrm{He}$ carrier gas. Neither $\mathrm{OH}$ groups nor hydrogen-bonded thiophene were detected (bands at $3610 \mathrm{~cm}^{-1}$ and $3200 \mathrm{~cm}^{-1}$, respectively), as expected from the absence of $\mathrm{OH}$ groups in Na-ZSM5 (Fig. 4). Infrared bands at $3150 \mathrm{~cm}^{-1}$ and $3100 \mathrm{~cm}^{-1}$ were observed (Fig. 4), indicating that a condensed thiophene phase is present within zeolite channels, as also found for H-ZSM5 and Co/H-ZSM5 (Fig. 2a and 2c). Similar conclusions were reported previously on NaY zeolite. ${ }^{27}$ On Na-ZSM5, however, another study ${ }^{5}$ assigned bands at 3109 and $3089 \mathrm{~cm}^{-1}$ to $\mathrm{C}-\mathrm{H}$ stretches and those at $1396 \mathrm{~cm}^{-1}$ to perturbed fundamental ring stretching vibrations $\nu_{5}$ in thiophene interacting strongly with $\mathrm{Na}^{+}$ cations. The bands corresponding to these modes may be present within the broad envelope of bands for condensed thio-

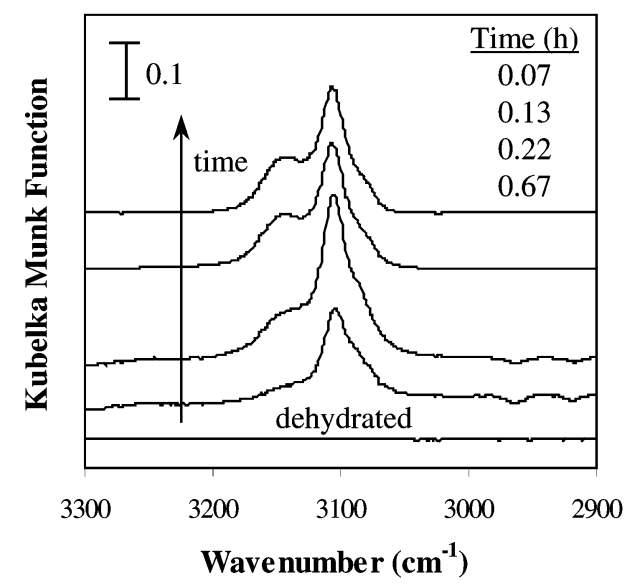

Fig. 4 Infrared spectra of Na-ZSM5 $(\mathrm{Si} / \mathrm{Al}=14.5)$ in contact with thiophene/He at $303 \mathrm{~K}$ with increasing time compared to spectrum of dehydrated sample in $\mathrm{He}$ at $773 \mathrm{~K}$. phene; yet, the shape of this envelope does not change, and no new features appear as the condensed thiophene phase desorbs as temperature increases from ambient to $573 \mathrm{~K}$. All thiophene-derived infrared bands disappeared without any intervening changes in frequency and without the appearance of new bands, as the temperature increased from ambient to $773 \mathrm{~K}$. Therefore, no ring opening and oligomerization reactions of thiophene-derived species were detected by the infrared measurements on Na-ZSM5.

\section{Temperature programmed desorption of pre-adsorbed thiophene}

The desorption of pre-adsorbed thiophene and the evolution of its reaction products were studied using $\mathrm{He}$ or $\mathrm{H}_{2}$ carrier gases as H-ZSM5, Co/H-ZSM5, and Na-ZSM5 samples were heated from ambient temperature to $773 \mathrm{~K}$. The amount of thiophene adsorbed during exposure to $1 \mathrm{kPa}$ thiophene at ambient temperature was measured from the differences in thiophene concentrations between inlet and outlet streams. The adsorption vs. time curves for thiophene in $\mathrm{He}$ and $\mathrm{H}_{2}$ carrier gases are similar in shape on H-ZSM5. They are also similar in shape for H-ZSM5, Co/H-ZSM5, and Na-ZSM5, but the amounts adsorbed differ. Saturation thiophene coverages were reached in $0.25-0.33 \mathrm{~h}$. After saturation, thiophene was removed from the carrier gas and the sample was purged with $\mathrm{He}$ for $1 \mathrm{~h}$ in order to remove weakly-adsorbed species. The amount of thiophene retained by the sample (Table 1) was estimated by subtracting the amount desorbed during the purge cycle from the amount adsorbed during exposure to the thiophene-containing stream.

The total amount of thiophene retained during the adsorption cycle corresponds to $\sim 2$ thiophene molecules per $\mathrm{Al}$ on all samples (Table 1). The infrared data shown in the previous section showed that ring opening and oligomerization occurred on H-ZSM5 and Co/H-ZSM5, but not on NaZSM5, during thiophene adsorption at ambient temperature (Fig. 1a-c). H-ZSM5 turned bright orange and Co/H-ZSM5 a paler orange color, during thiophene adsorption at ambient temperature, but Na-ZSM5 retained its original white color. Thiophene oligomers are colored and become darker as the extent of oligomerization increases, because electrons are more effectively delocalized over larger conjugated structures, leading to photon absorption in the visible range. Oligomers shift from colorless dimers, to pale yellow trimers, and ultimately to red for larger structures. ${ }^{28,29}$ The large amounts of thiophene formed and the color changes observed suggest the formation of oligomeric thiophene species during thiophene adsorption at ambient temperature on H-ZSM5 and Co/H-ZSM5, but not on Na-ZSM5.

Thiophene oligomerization occurs on acid catalysts. ${ }^{23-25}$ For example, thiophene forms predominantly trimers [2,4-di(2-thienyl)-thiolane] on phosphoric acid, ${ }^{23}$ and larger oligomers on cation-exchanged Y-zeolite and mordenite ${ }^{24}$ and on montmorillonite. ${ }^{25}$ On H-ZSM5 and Co/H-ZSM5, the extent of oligomerization becomes limited, apparently by the limited volume within ZSM5 channels, and the reaction stops after $\sim 0.3 \mathrm{~h}$ and saturation thiophene coverages are reached. Thiophene oligomers should not form on Na-ZSM5 because of the absence of acid sites; therefore, thiophene adsorbs molecularly within Na-ZSM5 pores, possibly via specific interactions with $\mathrm{Na}$ cations.

Infrared data showed that oligomerization and ring opening reactions form thiophene oligomers and alkene-thiol species, respectively, which give rise to infrared bands for $\mathrm{CH}_{2}$ groups near double bonds or sulfur atoms and to $\mathrm{SH}$ groups. These species appear to account also for the perturbation of the $\mathrm{OH}$ bands by hydrogen bonding. The formation of $\mathrm{CH}_{2}$ and $\mathrm{SH}$ species, however, would additionally require hydrogen transfer, intramolecularly within the thiophene structures or intermolecularly from neighboring adsorbed organic species. 
Table 1 Comparison of amounts of thiophene adsorbed, removed by $\mathrm{He}$ or $\mathrm{H}_{2}$, retained at room temperature, desorbed as thiophene during temperature programmed desorption, and desorbed as other products during temperature programmed desorption on $\mathrm{H}-\mathrm{ZSM} 5$, Co/H-ZSM5, and $\mathrm{Na}-\mathrm{ZSM} 5$ in $\mathrm{He}$ or $\mathrm{H}_{2}$ [1 $\mathrm{kPa}$ thiophene, balance $\mathrm{He}$ or $\left.\mathrm{H}_{2}, 303 \mathrm{~K}, \mathrm{Si} / \mathrm{Al}=14.5, \mathrm{Co} / \mathrm{Al}=0.12\right]$

\begin{tabular}{|c|c|c|c|c|c|c|}
\hline Catalyst & $\begin{array}{l}\text { Carrier } \\
\text { gas }\end{array}$ & $\begin{array}{l}\text { Thiophene adsorbed } \\
\text { (molecules/Al) }\end{array}$ & $\begin{array}{l}\text { Thiophene removed } \\
\text { (molecules/Al) }\end{array}$ & $\begin{array}{l}\text { Thiophene retained } \\
\text { (molecules } / \mathrm{Al} \text { ) }\end{array}$ & $\begin{array}{l}\text { Thiophene desorbed } \\
\text { Unreacted } \\
\text { (molecules/Al) }\end{array}$ & $\begin{array}{l}\text { Thiophene desorbed } \\
\text { as Other Products } \\
\text { (molecules/Al) }\end{array}$ \\
\hline H-ZSM5 & $\mathrm{He}$ & 1.85 & 0.23 & 1.62 & 0.38 & 0.072 \\
\hline H-ZSM5 & $\mathrm{H}_{2}$ & 1.91 & 0.48 & 1.43 & 0.61 & 0.0083 \\
\hline $\mathrm{Co} / \mathrm{H}-\mathrm{ZSM} 5$ & $\mathrm{He}$ & 2.33 & 0.56 & 1.77 & 0.76 & 0.10 \\
\hline $\mathrm{Co} / \mathrm{H}-\mathrm{ZSM} 5$ & $\mathrm{H}_{2}$ & 2.63 & 0.78 & 1.85 & 0.90 & 0.037 \\
\hline Na-ZSM5 & $\mathrm{He}$ & 2.14 & 0.49 & 1.65 & 0.95 & Not quantified \\
\hline
\end{tabular}

During purging, some weakly-adsorbed thiophene desorbs and the amounts of thiophene that remain adsorbed are shown in Table 1. The thiophene retained on H-ZSM5 and $\mathrm{Co} / \mathrm{H}-$ ZSM5 interacts with $\mathrm{OH}$ groups, leading to the replacement of the free acidic OH band in H-ZSM5 with a band for stretches of $\mathrm{OH}$ groups perturbed by hydrogen bonding with adsorbed thiophene or thiophene-derived species, such as oligothiophenes or alkene-thiols. Similar amounts of thiophene, however, remain on Na-ZSM5, even though this sample contains no acidic $\mathrm{OH}$ groups. The thiophene remaining after purging on Na-ZSM5 may be associated with $\mathrm{Na}$ cations ${ }^{5}$ or merely physisorbed on channel walls with a significant heat of adsorption.

After removal of weakly-bound thiophene at ambient temperature, the desorption of reaction products and of unreacted thiophene was monitored by online mass spectrometry as a function temperature (Fig. 5) using $\mathrm{He}$ as the carrier gas. Thiophene desorbs in two separate peaks centered at 400 and 575 $\mathrm{K}$; the second peak is much smaller than the first peak. Two desorption peaks were also observed when $\mathrm{H}_{2}$ was used as

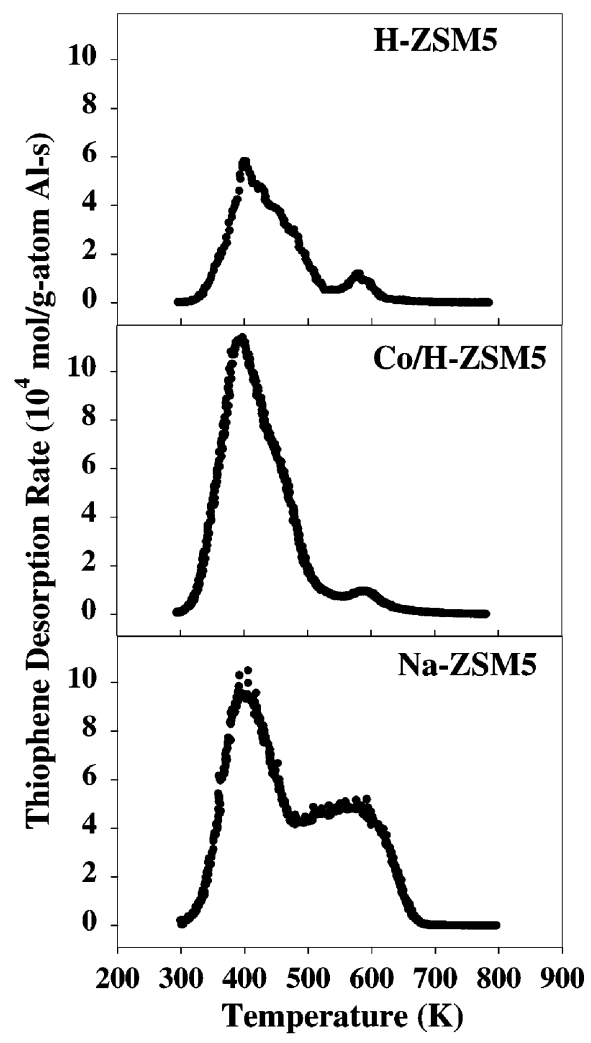

Fig. 5 Thiophene temperature programmed desorption in $\mathrm{He}$ on $\mathrm{H}$ ZSM5 $(\mathrm{Si} / \mathrm{Al}=14.5), \mathrm{Co} / \mathrm{H}-\mathrm{ZSM} 5(\mathrm{Co} / \mathrm{Al}=0.12)$, and Na-ZSM5 after adsorption of thiophene $\left[0.167 \mathrm{~K} \mathrm{~s}^{-1}, 1.67 \mathrm{~cm}^{3} \mathrm{~s}^{-1}\right]$. the carrier gas during thiophene desorption. On Na-ZSM5, unreacted thiophene also desorbed in two peaks, but the higher temperature peak accounted for a much larger fraction of the total amount of desorbed thiophene than on H-ZSM5 or $\mathrm{Co} / \mathrm{H}-\mathrm{ZSM} 5$. Previous studies have also reported two desorption peaks on Na-ZSM $5,{ }^{5}$ which were simply described as weakly and strongly adsorbed thiophene without any structural speculation.

The thiophene species desorbing at $\sim 400 \mathrm{~K}$ are likely to be bound to framework oxygens via van der Waals interactions, while the desorption peak at $575 \mathrm{~K}$ appears to reflect stronger interactions with specific sites, such as $\mathrm{Na}$ cations. Indeed, this desorption peak is much larger on Na-ZSM5 than on H-ZSM5 or Co/H-ZSM5, both of which contain only trace amounts of $\mathrm{Na}$. The amount of unreacted thiophene desorbed in the second peak (thiophene $/ \mathrm{Al}=0.03-0.04$ ) is similar to the amount of $\mathrm{Na}$ in $\mathrm{H}-\mathrm{ZSM} 5$ and $\mathrm{Co} / \mathrm{H}-\mathrm{ZSM} 5(\mathrm{Na} / \mathrm{Al} \sim 0.01-0.06)$. The corresponding amount desorbed for the Na-ZSM5 sample (thiophene $/ \mathrm{Al}=0.4)$, however, is less than expected from its $\mathrm{Na}$ content $(\mathrm{Na} / \mathrm{Al} \sim 1)$. We note that these desorption peaks do not include any adsorbed thiophene that has reacted to form stable adsorbed species.

Clearly, the species responsible for desorption of unreacted thiophene are not associated with acidic $\mathrm{OH}$ groups, because desorption profiles for H-ZSM5 and Co/H-ZSM5 are similar to those for Na-ZSM5 samples containing no framework Al$\mathrm{OH}$ species. Thus, it appears that the hydrogen-bonded thiophene species detected by infrared near ambient temperature undergo oligomerization and ring opening reactions before they desorb. Indeed, the amount of thiophene desorbed is much smaller than the amount retained after adsorption and purging at ambient temperature (Table 1). This is also the case for Na-ZSM5, for which the absence of acid sites makes the reasons for this behavior unclear. Garcia and Lercher have concluded that all adsorbed thiophene desorbs without reaction on Na-ZSM5. ${ }^{5}$

Table 1 also shows the amounts of thiophene retained and desorbed for H-ZSM5 and Co/H-ZSM5 when $\mathrm{H}_{2}$ was used as the carrier gas. The amounts of thiophene desorbed are greater when $\mathrm{H}_{2}$ is present on both $\mathrm{H}-\mathrm{ZSM} 5$ and $\mathrm{Co} / \mathrm{H}$ ZSM5 than when He is used as the carrier gas. This suggests that the reactions that strand thiophene on the surface are dehydrogenation reactions, such as oligomerization to dimer and trimer thiophene species and ring opening reactions to form alkene-thiol species, the products of which can be hydrogenated to form desorbable hydrocarbons and $\mathrm{H}_{2} \mathrm{~S}$ when $\mathrm{H}_{2}$ is available as a reactant.

Several products were detected during heating of these samples after thiophene adsorption. $\mathrm{H}_{2} \mathrm{~S}$ formed slightly above ambient temperature (Fig. 6a) on both $\mathrm{H}-\mathrm{ZSM} 5$ and $\mathrm{Co} / \mathrm{H}-$ ZSM5. The amounts of $\mathrm{H}_{2} \mathrm{~S}$ desorbed are plotted in relative units (signal intensity for $34 \mathrm{amu}$ relative to $4 \mathrm{amu}$ ) because a calibration of the mass spectrometer for $\mathrm{H}_{2} \mathrm{~S}$ was unavailable. This low-temperature pathway for $\mathrm{H}_{2} \mathrm{~S}$ formation is consistent with the ring opening reactions detected near ambient 

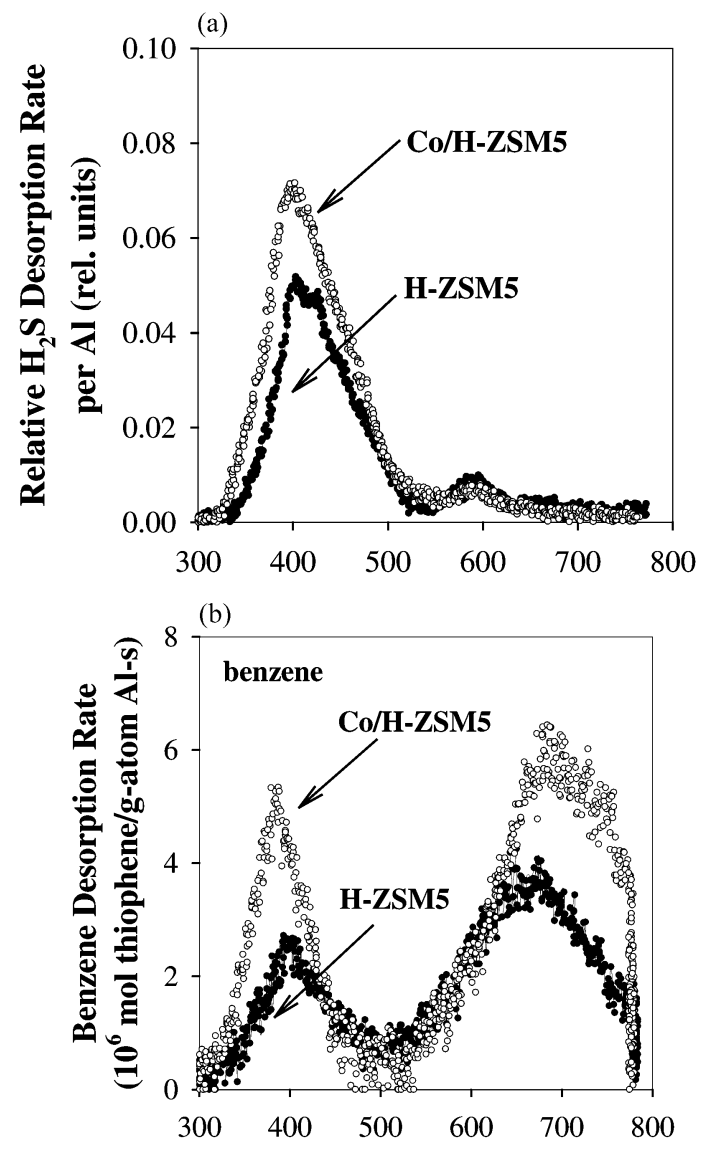

(c)

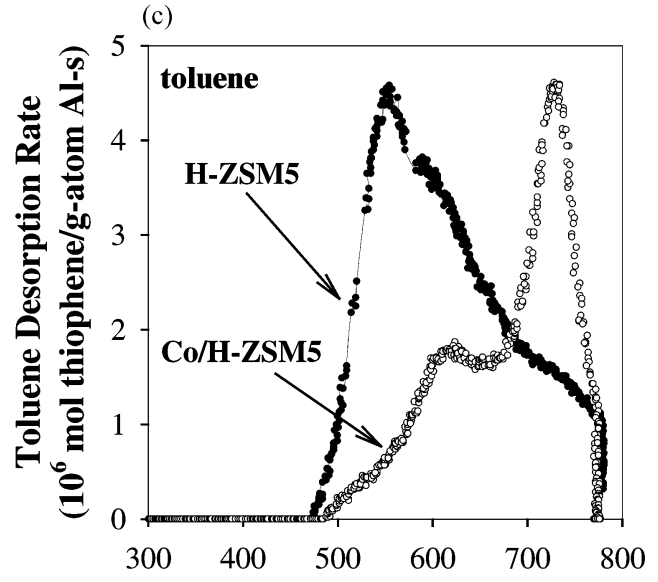

Temperature (K)

Fig. 6 (a) $\mathrm{H}_{2} \mathrm{~S}$ desorption rates relative to $\mathrm{He}$ (per $\mathrm{Al}$ ) during temperature programmed desorption of pre-adsorbed thiophene on $\mathrm{H}$ ZSM5 and on Co/H-ZSM5 using $\mathrm{He}$ as a carrier gas $[\mathrm{Si} / \mathrm{Al}=14.5$, $\mathrm{Co} / \mathrm{Al}=0.12,0.167 \mathrm{~K} \mathrm{~s}^{-1}, 1.67 \mathrm{~cm}^{3} \mathrm{~s}^{-1}$, isothermal at $773 \mathrm{~K}$ for 1 h]. (b) Benzene desorption rates during temperature programmed desorption of pre-adsorbed thiophene on H-ZSM5 and on Co/H-ZSM5 using $\mathrm{He}$ as a carrier gas $\left[\mathrm{Si} / \mathrm{Al}=14.5, \mathrm{Co} / \mathrm{Al}=0.12,0.167 \mathrm{~K} \mathrm{~s}^{-1}\right.$, $1.67 \mathrm{~cm}^{3} \mathrm{~s}^{-1}$, isothermal at $773 \mathrm{~K}$ for $\left.1 \mathrm{~h}\right]$. (c) Toluene desorption rates during temperature programmed desorption of pre-adsorbed thiophene on H-ZSM5 and on Co/H-ZSM5 using $\mathrm{H}_{2}$ as a carrier gas $\left[\mathrm{Si} / \mathrm{Al}=14.5, \mathrm{Co} / \mathrm{Al}=0.12,0.167 \mathrm{~K} \mathrm{~s}^{-1}, 1.67 \mathrm{~cm}^{3} \mathrm{~s}^{-1}\right.$, isothermal at $773 \mathrm{~K}$ for $1 \mathrm{~h}$ ].

temperature by infrared spectroscopy. Benzene also desorbs immediately upon heating, suggesting that it forms from thiophene-derived fragments that remain after ring opening and desulfurization (Fig. 6b). Benzene molecules have a higher $\mathrm{H}: \mathrm{C}$ ratio than thiophene molecules desulfurized via intramolecular hydrogen transfer, suggesting that hydrogen transfer from co-adsorbed species must occur, leaving behind highly unsaturated and strongly-bound organic fragments. Benzene (Fig. 6b), toluene, methylthiophene, benzothiophene, and light alkenes (ethene and propene) also desorb at somewhat higher temperatures. Interestingly, only small amounts of $\mathrm{H}_{2} \mathrm{~S}$ desorb at these high temperatures, indicating that most of the sulfur removal had already occurred at lower temperatures and that the hydrocarbons desorbed at higher temperatures were formed at lower temperatures. With $\mathrm{He}$ as the carrier, $\mathrm{H}_{2} \mathrm{~S}$ (Fig. 6a), benzene (Fig. 6b), and benzothiophene desorb at similar temperatures on $\mathrm{H}-\mathrm{ZSM} 5$ and $\mathrm{Co} / \mathrm{H}$ ZSM5, while toluene and methylthiophene desorb at slightly higher temperatures on $\mathrm{Co} / \mathrm{H}-\mathrm{ZSM} 5$ than on $\mathrm{H}-\mathrm{ZSM} 5$. This is consistent with the infrared results, which showed that adsorbed species are retained to higher temperatures on $\mathrm{Co} /$ H-ZSM5 than on H-ZSM5 (Fig. 3). The presence of Co cations appears to lead to more unsaturated intermediates by providing sites for the removal of hydrogen as $\mathrm{H}_{2} \cdot{ }^{11,30}$ Cations do not appear to influence desulfurization pathways or to provide active sites for desulfurization of pre-adsorbed thiophene.

With $\mathrm{H}_{2}$ as the carrier gas, reaction pathways were similar to those with $\mathrm{He}$ on $\mathrm{H}-\mathrm{ZSM} 5$, except that larger amounts of benzene evolved in a single peak at the same temperature as the second peak observed when $\mathrm{He}$ was used as the carrier gas. $\mathrm{H}_{2} \mathrm{~S}$ evolution curves were identical with $\mathrm{H}_{2}$ and $\mathrm{He}$ (not shown). Benzene and toluene (Fig. 6c) evolved at higher temperatures on $\mathrm{Co} / \mathrm{H}-\mathrm{ZSM} 5$ than on $\mathrm{H}-\mathrm{ZSM} 5$ when $\mathrm{H}_{2}$ is used as the carrier and the amount of benzene formed is much higher on $\mathrm{Co} / \mathrm{H}-\mathrm{ZSM} 5$ than on H-ZSM5. This appears to reflect a role of Co cations in dissociating $\mathrm{H}_{2}$ and leading to the hydrogenation of unsaturated organic residues, which become stranded in the absence of such hydrogenation reactions. Co cations influence product evolution temperatures, but not the identity of the products formed or the thiophene reaction pathways. Previous mechanistic studies have also shown that Co cations influence the rate but not the pathways of desulfurization reactions using propane or $\mathrm{H}_{2}$ as a hydrogen source. ${ }^{3}$

The total amounts of hydrocarbon products desorbed from $\mathrm{H}-\mathrm{ZSM} 5$ and $\mathrm{Co} / \mathrm{H}-\mathrm{ZSM} 5$ in $\mathrm{He}$ and in $\mathrm{H}_{2}$ are reported in Table 1. Reactions of adsorbed thiophene using $\mathrm{He}$ as the carrier gas led to a larger number of products, because the absence of $\mathrm{H}_{2}$ favors reactions among thiophene-derived adsorbed intermediates, and to the formation of a wide range of larger organosulfur compounds (Table 1). In contrast, the use of Co cations as $\mathrm{H}_{2}$ activation sites led to larger amounts of hydrocarbons and to the more prevalent removal of sulfur as $\mathrm{H}_{2} \mathrm{~S}$ (Table 1). The amount of thiophene desorbed as hydrocarbons and organosulfur compounds is smaller than the total amount of thiophene initially adsorbed; it is also smaller than the amount of thiophene that desorbs unreacted (Table 1). The stranded thiophene appears to consist of oligomers or dehydrogenated debris from ring opening reactions, which cannot desorb and become sources of hydrogen for hydrogenation and desorption of thiophene-derived species.

After thermal treatments in $\mathrm{He}$ (Fig. 6a and 6b) or $\mathrm{H}_{2}$ (Fig. $6 c)$, the samples were cooled to ambient temperature and heated in $\mathrm{H}_{2}$ to $873 \mathrm{~K}$ at $1.67 \mathrm{~K} \mathrm{~s}^{-1}$. Samples were cooled again to ambient temperature and heated in air to $873 \mathrm{~K}$ at $1.67 \mathrm{~K} \mathrm{~s}^{-1}$. During both treatments, the evolution of products was monitored by mass spectrometry. During $\mathrm{H}_{2}$ treatment, benzene and toluene were detected as major products and methane, ethene, ethane, propene, and propane in trace amounts. The amounts of products formed were much smaller than those formed during the initial desorption experiments (Table 1, Fig. 6a-c). During the subsequent air treatment, $\mathrm{CO}_{2}$ and $\mathrm{SO}_{2}$ were detected, but their concentrations could not be measured because of their small amounts and unavailable calibrations. No $\mathrm{H}_{2} \mathrm{O}$ was detected, suggesting the absence of hydrogen atoms in the residual organic species. However, the sensitivity for $\mathrm{H}_{2} \mathrm{O}$ was low because of a ubiquitous water background signal in the mass spectrometer. 


\section{In situ infrared spectroscopic studies}

The previous infrared and temperature programmed desorption studies focused on adsorption and reactions of preadsorbed thiophene. Here, we show infrared spectra collected during steady-state thiophene reactions at $773 \mathrm{~K}$ on $\mathrm{H}$ ZSM5 and Co/H-ZSM5 using He or propane as additional gas phase components. Fig. 7 shows infrared spectra for $\mathrm{H}$ ZSM5 during catalytic decomposition of thiophene-He mixtures at $773 \mathrm{~K}$ as a function of time on stream; an initial spectrum of the H-ZSM5 sample before exposure to thiophene is also shown. Only free acidic $\mathrm{OH}$ bands $\left(3610 \mathrm{~cm}^{-1}\right)$ are detected during reactions of thiophene-He mixtures on $\mathrm{H}$ ZSM5 at $773 \mathrm{~K}$ and the intensities of these bands are identical to those in the fresh H-ZSM5 sample before contact with thiophene. The absence of new bands and the unchanged intensity and frequency of the $\mathrm{OH}$ infrared band at $3610 \mathrm{~cm}^{-1}$ show that the amount of thiophene and of its reaction products adsorbed on acidic $\mathrm{OH}$ groups is very low during steady-state thiophene decomposition at $773 \mathrm{~K}$.

Fig. 8 shows the corresponding infrared spectra for $\mathrm{H}$ ZSM5 during steady-state reactions of thiophene-propane mixtures at $773 \mathrm{~K}$ as a function of time on stream. Several poorly resolved bands appear at $\sim 2980 \mathrm{~cm}^{-1}$ upon contact of the sample with the reactant mixture at $773 \mathrm{~K}$. These bands correspond to propane molecules present in the gas phase

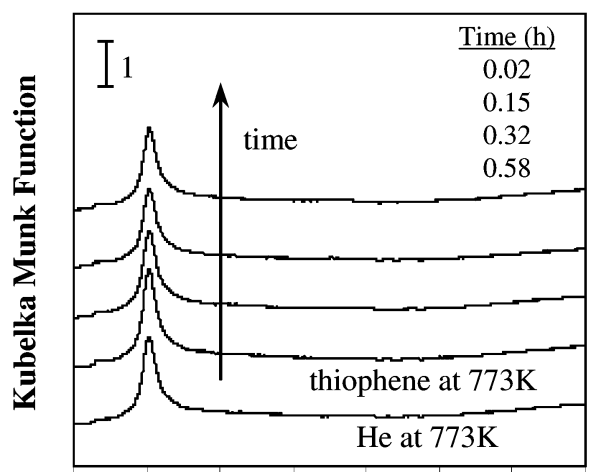

$\begin{array}{llllllll}3800 & 3600 & 3400 & 3200 & 3000 & 2800 & 2600 & 2400\end{array}$

Wavenumber $\left(\mathrm{cm}^{-1}\right)$

Fig. 7 Infrared spectra of $\mathrm{OH}$ region of $\mathrm{H}-\mathrm{ZSM} 5(\mathrm{Si} / \mathrm{Al}=14.5)$ in contact with thiophene/He at $773 \mathrm{~K}$ with increasing time compared to spectrum of dehydrated sample in $\mathrm{He}$ at $773 \mathrm{~K}$.

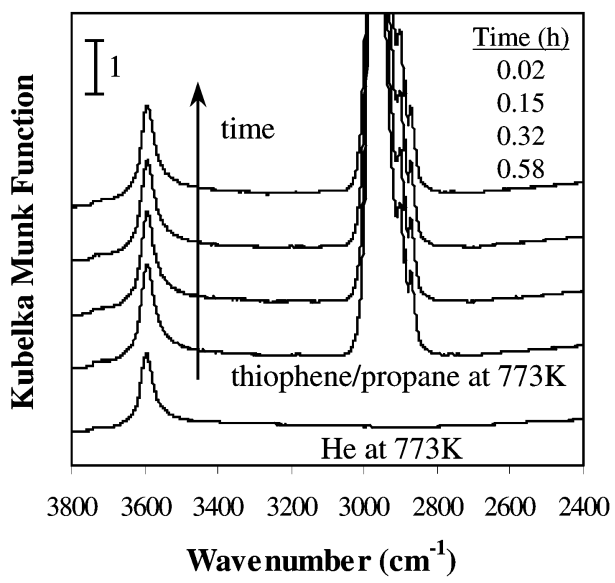

Fig. 8 Infrared spectra of $\mathrm{OH}$ region of $\mathrm{H}-\mathrm{ZSM} 5(\mathrm{Si} / \mathrm{Al}=14.5)$ in contact with thiophene-propane-He at $773 \mathrm{~K}$ with increasing time compared to spectrum of dehydrated sample in $\mathrm{He}$ at $773 \mathrm{~K}$. within the beam path. The $\mathrm{OH}$ band intensities during steady-state catalysis were identical to those in the fresh sample. As in the case of reactions of pure thiophene, catalytic surfaces appear to remain largely uncovered by adsorbed species derived from propane and thiophene during these catalytic reactions on H-ZSM5

Infared spectra were also measured on Co/H-ZSM5 samples during reactions of thiophene and thiophene-propane mixtures at $773 \mathrm{~K}$. These spectra also failed to show any detectable adsorbed species or any changes in the number of free acidic $\mathrm{OH}$ groups during steady-state catalysis. Co cations do not appear to introduce binding sites capable of stabilizing infrared-active adsorbed thiophene or thiophene-derived intermediates during these catalytic reactions.

In summary, acidic $\mathrm{OH}$ groups remain predominantly unoccupied during catalytic reactions at $773 \mathrm{~K}$ and no infraredactive adsorbed species are introduced by Co cations. Thiophene has been shown to inhibit propane reactions on $\mathrm{Co} /$ $\mathrm{H}-\mathrm{ZSM} 5$ through a decrease in the availability or the reactivity of $\mathrm{Co}$ or $\mathrm{OH}$ sites. ${ }^{3}$ Inhibition effects caused by blockage of acidic $\mathrm{OH}$ groups would have been detected as a perturbation of the $\mathrm{OH}$ stretching modes, while interactions between $\mathrm{Co}$ cations and thiophene-derived intermediates would have led to new absorption infrared bands, unless such deactivating residues have very low absorption cross-sections or no residual $\mathrm{C}-\mathrm{H}$ bonds. The observed inhibition effects on bifunctional dehydrocyclodimerization reactions ${ }^{3}$ are not caused by blockage of acidic $\mathrm{OH}$ sites. Cations were previously shown to increase the rate of thiophene desulfurization using propane as co-reactants. ${ }^{1,2}$ Here, we show that interactions between thiophene and Co sites do not lead to any adsorbed species detectable by infrared.

\section{In situ Co K-edge XANES}

In situ Co K-edge X-ray absorption near-edge spectroscopy was used to probe the local structure of the Co cations in $\mathrm{Co} / \mathrm{H}-\mathrm{ZSM} 5$ and to detect any changes in coordination or adsorbate coverage caused by thiophene-propane reactions. The local structure of Co cations in fresh and dehydrated $\mathrm{Co} / \mathrm{H}-\mathrm{ZSM} 5$ samples was previously examined using X-ray absorption spectroscopy. ${ }^{13}$ These studies showed that Co cations are present at cation exchange sites as well dispersed divalent cations with tetrahedral coordination after dehydration and during reactions in $\mathrm{H}_{2}$ or $\mathrm{C}_{3} \mathrm{H}_{8}$ at $773 \mathrm{~K} .{ }^{13} \mathrm{D}_{2}-\mathrm{OH}$ and infrared measurements showed that one $\mathrm{Co}^{2+}$ cation replaces 1.1-1.3 $\mathrm{OH}$ groups, suggesting the presence of $\mathrm{Co}$ dimers and some monomers, each interacting with two next nearest neighbor $\mathrm{Al}$ framework sites. ${ }^{13}$

The near-edge spectrum of $\mathrm{Co} / \mathrm{H}-\mathrm{ZSM} 5$ during reaction at $773 \mathrm{~K}$ is shown in Fig. 9a; the corresponding spectra for $\mathrm{Co} /$ H-ZSM5 after dehydration, for Co metal, and for Co sulfide are also shown. The spectra for Co/H-ZSM5 during reaction resemble that of the dehydrated sample. Difference spectra between the sample during reaction and the dehydrated sample, and the Co and Co sulfide standards are shown in Fig. 9b. The difference between the spectra during reaction and the dehydrated fresh sample suggests a slight distortion of the $\mathrm{Co}^{2+}$ structure, possibly as a result of adsorbed species interacting with these cations. These differences appear to reverse partially some of the changes in the near-edge spectra observed during thermal treatment of fresh samples exposed to ambient air. These thermal treatments remove water molecules coordinated to $\mathrm{Co}^{2+}$ cations. Thus, it appears that some species adsorb on these cations during propane-thiophene reactions at $773 \mathrm{~K}$. The large near-edge spectrum differences between the sample during thiophene-propane reactions and Co metal or Co sulfide show that the oxidation state and local coordination of $\mathrm{Co}$ cations during reaction differ markedly from those in Co metal and Co sulfide structures (Fig. 9b). 


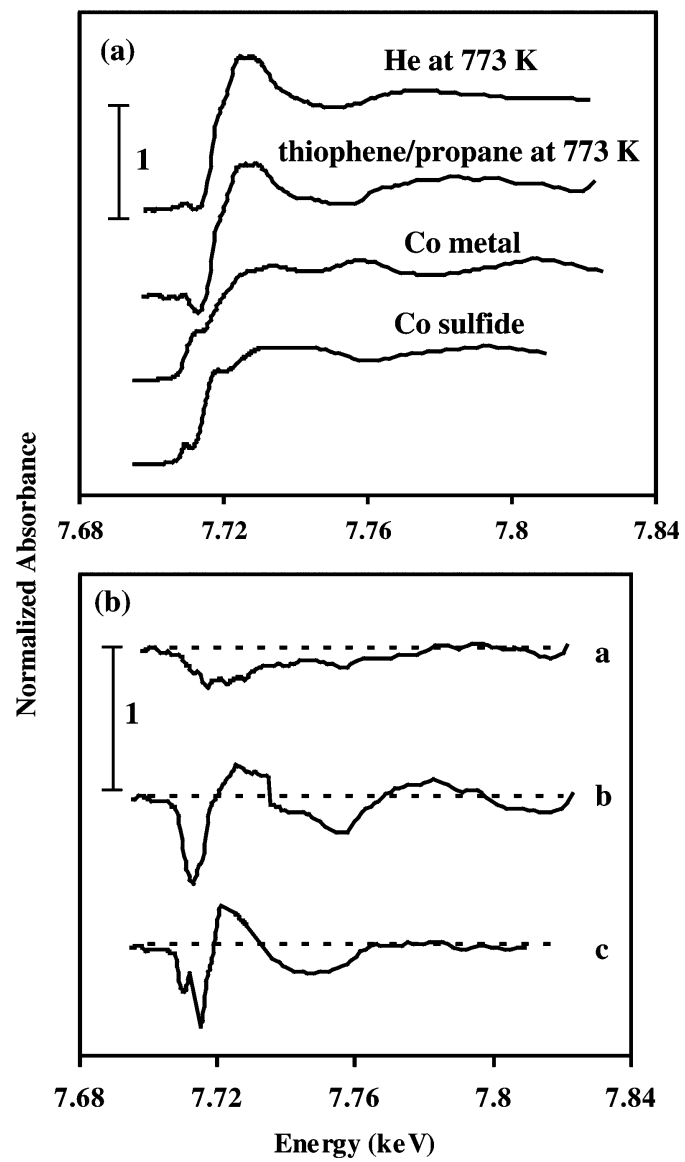

Fig. 9 (a) Co K-edge XANES of Co/H-ZSM5 dehydrated in $\mathrm{He}$ at $773 \mathrm{~K}, \mathrm{Co} / \mathrm{H}-\mathrm{ZSM} 5$ during thiophene-propane reaction at $773 \mathrm{~K}$, Co metal, and Co sulfide. (b) Difference spectra of: a, Co K-edge XANES of Co/H-ZSM 5 during thiophene-propane reaction at 773 $\mathrm{K}$ and of $\mathrm{Co} / \mathrm{H}-\mathrm{ZSM} 5$ dehydrated in $\mathrm{He}$ at $773 \mathrm{~K}$; b, Co K-edge XANES of $\mathrm{Co} / \mathrm{H}-\mathrm{ZSM} 5$ during thiophene-propane reaction at 773 $\mathrm{K}$ and of $\mathrm{Co}$ metal; and c, Co K-edge XANES of Co/H-ZSM5 during thiophene-propane reaction at $773 \mathrm{~K}$ and of Co sulfide.

In summary, slight changes in the structure of Co cations were detected by X-ray absorption spectroscopy during thiophene-propane reactions, possibly due to adsorbed species, but $\mathrm{Co}^{2+}$ cations remain at exchange sites in the presence of thiophene-propane mixtures at $773 \mathrm{~K}$. Co cations in $\mathrm{Co} / \mathrm{H}-$ ZSM5 also do not reduce in $\mathrm{H}_{2}$ or propane at $773 \mathrm{~K}$, and their local coordination remains unchanged during these treatments. ${ }^{13}$ Temperature programmed reduction studies confirmed that $\mathrm{Co}^{2+}$ cations remain as divalent cations in $\mathrm{H}_{2}$ even at $1273 \mathrm{~K}^{13}$

\section{Sulfur K-edge XANES}

Sulfur K-edge X-ray absorption near-edge spectra (XANES) can discern the type of sulfur compounds present in a sample,

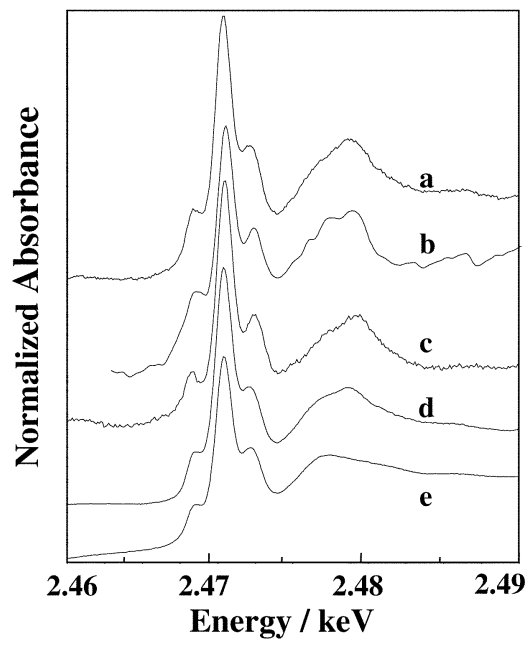

Fig. 10 Sulfur K-edge XANES of H-ZSM5 after reactions of (a) 1 $\mathrm{kPa} \mathrm{C}_{4} \mathrm{H}_{4} \mathrm{~S}, 20 \mathrm{kPa} \mathrm{C}_{3} \mathrm{H}_{8}$, balance $\mathrm{He}$ (b) $3 \mathrm{kPa} \mathrm{C}_{4} \mathrm{H}_{4} \mathrm{~S}$, balance $\mathrm{He}$ (c) $3 \mathrm{kPa} \mathrm{C}_{4} \mathrm{H}_{4} \mathrm{~S}, 1-5 \mathrm{kPa} \mathrm{H}$, balance $\mathrm{He}$ (d) $3 \mathrm{kPa} \mathrm{C}_{4} \mathrm{H}_{4} \mathrm{~S}, 150 \mathrm{kPa}$ $\mathrm{H}_{2}$, balance $\mathrm{He}$ (e) $3 \mathrm{kPa} \mathrm{C}_{4} \mathrm{H}_{4} \mathrm{~S}, 20 \mathrm{kPa} \mathrm{C}_{3} \mathrm{H}_{8}$, balance $\mathrm{He}$ [Si/ $\mathrm{Al}=14.5,773 \mathrm{~K}]$.

because these spectra are very sensitive to the oxidation state and chemical environment of sulfur atoms. ${ }^{31-33}$ Here, sulfur K-edge X-ray absorption spectra were measured for samples used in thiophene, thiophene- $\mathrm{H}_{2}$, and thiophene-propane reactions at $773 \mathrm{~K}$ for several hours. These spectra were used to estimate the type and concentration of sulfur compounds remaining on samples after reaction. The sulfur K-edge position is sensitive to the sulfur oxidation state and to the type of sulfur species present. The edge height of the absorption edge before normalization is proportional to the concentration of sulfur absorbers in the sample.

Fig. 10 shows normalized sulfur K-edge near-edge spectra for H-ZSM5 samples after reactions of thiophene, thiophene- $\mathrm{H}_{2}$, and thiophene-propane mixtures. The spectra for these three samples are very similar, indicating that similar types of sulfur species remain after each of these reactions. The edge energies (2468-2477 eV) correspond to sulfur atoms in organic compounds and the concentrations of these species are reported in Table 2 as $[\mathrm{S}: \mathrm{Al}]$ atomic ratios. The amount of residual sulfur increased with increasing thiophene concentration in thiophene-propane mixtures. The presence of $\mathrm{H}_{2}$ $(150 \mathrm{kPa})$ or propane $(20 \mathrm{kPa})$ leads to lower residual sulfur contents, because these co-reactants provide hydrogen species that hydrogenate and desorb organosulfur compounds.

The near-edge spectra for several cation-exchanged $\mathrm{H}$ ZSM5 samples after thiophene-propane reactions at $773 \mathrm{~K}$ are shown in Fig. 11. These spectra show that the adsorbed sulfur compounds are similar on Zn/H-ZSM5, Co/H-ZSM5, and H-ZSM5. Thus, cations do not appear to influence the type of organosulfur species retained by these samples during thiophene-propane reactions. This seems to confirm that cations do not influence the pathways involved in thiophene-

Table 2 Sulfur content and sulfur/ $\mathrm{Al}(\mathrm{S}: \mathrm{Al})$ ratio of $\mathrm{H}-\mathrm{ZSM} 5$ after thiophene, thiophene- $\mathrm{H}_{2}$, and thiophene-propane reactions $[\mathrm{Si} / \mathrm{Al}=14.5$, $773 \mathrm{~K}]$

\begin{tabular}{llllll}
\hline & \multicolumn{2}{l}{ Pressure $/ \mathrm{kPa}$} & & & \\
\cline { 2 - 5 } & Thiophene & $\mathrm{H}_{2}$ & Propane & Sulfur wt.\% & S : Al ratio \\
\hline A & 1 & 0 & 20 & 0.11 & 0.032 \\
$\mathrm{~B}$ & 3 & 0 & 0 & 0.92 & 0.27 \\
$\mathrm{C}$ & 3 & $1-5$ & 0 & 0.3 & 0.38 \\
$\mathrm{D}$ & 3 & 150 & 0 & 0.13 & 0.15 \\
$\mathrm{E}$ & 3 & 0 & 20 & 0.14 & 0.041 \\
\hline
\end{tabular}


Table 3 Sulfur content, sulfur : Al (S : Al) ratio, and sulfur : metal (S : M) ratio of H-ZSM5, Zn/H-ZSM5, and Co/H-ZSM5 after thiophenepropane reactions $\left[773 \mathrm{~K}, 1 \mathrm{kPa} \mathrm{C} \mathrm{H}_{4} \mathrm{~S}, 20 \mathrm{kPa} \mathrm{C} \mathrm{H}_{8}\right]$. Preparation and characterization details of the $\mathrm{Zn} / \mathrm{H}-\mathrm{ZSM} 5$ sample were reported previously 1

\begin{tabular}{llll}
\hline Catalyst & M : Al ratio & Sulfur wt. \% & S : Al ratio \\
\hline H-ZSM5 & - & 0.11 & 0.032 \\
Zn/ H-ZSM5 & 0.15 & 0.09 & 0.026 \\
Co/ H-ZSM5 & 0.07 & 0.06 & 0.017 \\
\hline
\end{tabular}

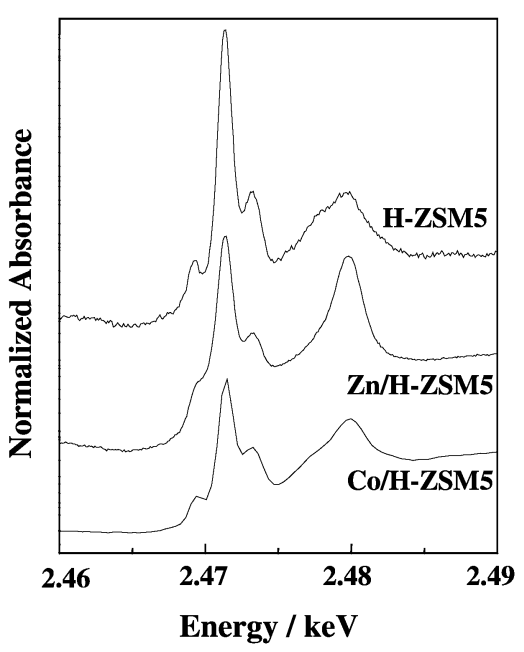

Fig. 11 Sulfur K-edge XANES of H-ZSM5, Zn/H-ZSM5, and Co/ $\mathrm{H}-Z \mathrm{ZSM} 5$ after thiophene-propane reactions $\left[773 \mathrm{~K}, 1 \mathrm{kPa} \mathrm{C}_{4} \mathrm{H}_{4} \mathrm{~S}\right.$, $20 \mathrm{kPa} \mathrm{C} \mathrm{H}_{3}$, balance He]. Preparation and characterization details of the $\mathrm{Zn} / \mathrm{H}-\mathrm{ZSM} 5$ sample were reported previously. ${ }^{1}$

propane reactions. ${ }^{3}$ No inorganic sulfides were apparent in any of the samples, as also concluded from the nearly unchanged structure of Co cations during reaction. Co cations are stable against sulfidation and reduction during thiophene-propane reactions in which $\mathrm{H}_{2} \mathrm{~S}$ is formed and present.

The sulfur to aluminum ( $\mathrm{S}: \mathrm{Al})$ and sulfur to cation $(\mathrm{S}: \mathrm{M})$ atomic ratios in these samples are reported in Table 3 . The amounts of sulfur remaining after thiophene-propane reactions on H-ZSM5, Co/H-ZSM5, and Zn/H-ZSM5 account for less than $1 \%$ of the amount of sulfur removed from thiophene as $\mathrm{H}_{2} \mathrm{~S}$, confirming that these materials act as catalysts and not as sulfur traps that merely bind thiophene-derived sulfur species.

\section{Conclusions}

Infrared spectroscopic studies showed that thiophene interacts with acidic $\mathrm{OH}$ groups of $\mathrm{H}-\mathrm{ZSM} 5$ and $\mathrm{Co} / \mathrm{H}-\mathrm{ZSM} 5$ and that ring opening and oligomerization occur near ambient temperature. No bands corresponding to thiophene interactions with Co cations were detected, but they may have been obscured by broad bands for condensed thiophene. Temperature programmed desorption studies did not detect any thiophene interactions with Co cations. Some unreacted thiophene desorbs during temperature ramping. These arise from thiophene physisorbed on channel walls or interacting with residual $\mathrm{Na}$ cations. Most of the thiophene adsorbed at ambient temperature did not desorb unreacted, but reactions products, such as $\mathrm{H}_{2} \mathrm{~S}$ and benzene, were detected at relatively low temperatures by mass spectrometry and thiophene oligomers were apparent from the color changes in the samples during thiophene adsorption. Infared spectra during propane-thiophene reactions at $773 \mathrm{~K}$ did not detect significant coverages of adsorbed species interacting with acidic $\mathrm{OH}$ groups or any bands asso- ciated with organic species interacting with Co cations. Sulfur K-edge X-ray absorption spectra showed that organic sulfur species remain on samples after thiophene-propane reactions, but inorganic sulfides were not detected. The amount of retained organic sulfur is less than $1 \%$ of that removed from thiophene as $\mathrm{H}_{2} \mathrm{~S}$. Co cations at exchange sites do not sulfide or reduce during reactions. X-ray absorption at the Co K-edge confirmed that Co cations are stable against sulfidation and reduction in the presence of thiophene-propane mixtures at $773 \mathrm{~K}$. The local structure of the Co cations is slightly different, however, from that in fresh samples, apparently as a result of strongly adsorbed species interacting with the exchanged $\mathrm{Co}^{2+}$ cations.

\section{Acknowledgement}

This work was supported by the National Science Foundation (CTS-96-13632) under the technical supervision of Drs Raul Miranda and Geoffrey Prentice. X-Ray absorption data were collected at Stanford Synchrotron Radiation Laboratory (SSRL), a facility operated by the United States Department of Energy (DOE), Office of Basic Energy Sciences, under contract DE-ACO03-76SF00515. Javier Garcia-Martinez would like to thank the Ministerio de Educación, Cultura y Deportes de España for a FPI fellowship.

\section{References}

1 S. Y. Yu, W. Li and E. Iglesia, J. Catal., 1999, 187, 257.

2 W. Li, S. Y. Yu and E. Iglesia, Stud. Surf. Sci. Catal., 2000, 130, 899.

3 W. Li, S. Y. Yu and E. Iglesia, J. Catal., 2001, 175, 203.

4 W. Li, S. Y. Yu and E. Iglesia, J. Catal., in press.

5 C. L. Garcia and J. A. Lercher, J. Phys. Chem., 1992, 96, 2669.

6 C. L. Garcia and J. A. Lercher, J. Mol. Struct., 1993, 293, 235.

7 F. Geobaldo, G. T. Palomino, S. Bodiga, A. Zecchina and C. O. Arean, Phys. Chem. Chem. Phys., 1999, 1, 561.

8 G. Spoto, F. Geobaldo, S. Bordiga, C. Lamberti, D. Scarano and A. Zecchina, Top. Catal., 1999, 8, 279.

9 P. Mills, D. C. Phillips, B. P. Woodruff, R. Main and M. E. Bussell, J. Phys. Chem. B, 2000, 104, 3237.

10 P. Mills, S. Korlann, M. Bussell, M. A. Reynolds, M. V. Ovchinnikov, R. J. Angelici, C. Sinner, T. Weber and R. Prins, J. Phys. Chem. A., 2001, 105, 4418.

11 J. A. Biscardi, G. D. Meitzner and E. Iglesia, J. Catal., 1998, 179, 192.

12 R. W. Borry, Y. H. Kim, A. Huffsmith, J. A. Reimer and E. Iglesia, J. Phys. Chem. B, 1999, 103, 5787.

13 W. Li, S. Y. Yu, G. D. Meitzner and E. Iglesia, J. Phys. Chem. B, 2001, 105, 1176

14 P. Kubelka and F. Munk, Z. Tech. Phys., 1931, 12, 593.

15 D. G. Barton, PhD Thesis, University of California, Berkeley, 1998.

16 T. Ressler, WinXAS, 1998.

17 T. Ressler, J. Synch. Rad., 1998, 5, 118.

18 E. A. Stearn and S. M. Heald, Rev. Sci. Instrum., 1979, 50, 1579.

19 P. Jacobs and R. von Ballmos, J. Phys. Chem., 1982, 86, 3050.

20 S. M. Campbell, D. M. Bibby, J. M. Coddington, R. F. Howe and R. H. Meinhold, J. Catal., 1996, 161, 338.

21 S. B. Pu and T. Inui, Zeolites, 1997, 19, 452. 
22 X. Saintigny, R. A. van Santen, S. Clemendot and F. Hutschka, J. Catal., 2001, 200, 79

23 S. L. Meisel, G. C. Johnson and H. D. Hartough, J. Am. Chem. Soc., 1950, 72, 1910.

24 P. Enzel and T. Bein, J. Chem. Soc., Chem. Commun., 1989, 1326.

25 V. Lorprayoon and R. A. S. Condrate, Appl. Spectrosc., 1982, 36, 696.

26 W. Li, J. A. Biscardi, S. Y. Yu and E. Iglesia, unpublished results.

27 B. A. De Angelis and G. Appierto, J. Colloid Interface Sci., 1975, 53, 14.

28 J. Nakayama, T. Konishi, S. Murabayashi and M. Hoshino, Heterocycles, 1987, 26, 1793.
29 D. Fichou, Handbook of Oligo- and Polythiophenes, Wiley-VCH, Weinheim, Germany, 1999.

30 S. Y. Yu, G. J. Yu, W. Li and E. Iglesia, J. Phys. Chem., in press.

31 G. N. George and M. L. Gorbaty, J. Am. Chem. Soc., 1989, 111 3182

32 N. E. J. Pingitore, G. Meitzner and K. M. Love, Geochim. Cosmochim. Acta, 1995, 59, 2477.

33 A. Vairavamurthy, B. Manowitz, W. Zhiu, and Y. Jeon, Environmental Geochemistry of Sulfide Oxidation, C. N. Alpers and D. W. Blowes, American Chemical Society, Washington DC, 1994. 